\title{
In vitro Analysis Comparing Efficacy of Lasers and Desensitizing Agents on Dentin Tubule Occlusion: A Scanning Electron Microscope Study
}

\author{
${ }^{1}$ Arulmozhi Nandakumar, ${ }^{2}$ Vidyaa Hari lyer
}

\begin{abstract}
Dentinal hypersensitivity (DH), one of the commonest causes of dental pain, arises from exposure of dentinal tubules most commonly in the cervical region of the buccal and facial surfaces of the tooth in response to typically thermal, evaporative, tactile, osmotic or chemical stimulus. This study aims at evaluating the efficacy of Er,Cr:YSGG (dual lasers - hard and soft tissue) and diode lasers (soft tissue lasers) against clinically proven dentifrices prescribed by dentists, easily available over the counter, in treating $\mathrm{DH}$. In 60 recently extracted human teeth, cervical cavities were prepared and etched with $17 \%$ EDTA to expose the tubules and eliminate smear layer. The teeth were further divided into groups: Er,Cr:YSGG laser, diode laser and commonly used dentifrices chosen on the basis of previous studies. After treatment, the teeth were subjected for scanning electron microscope (SEM) analysis on the same day for quantitative and qualitative analysis of the specimens. Quantitative analysis of the SEM images was done using image analysis software. Er,Cr:YSGG showed superior results in terms of number of tubules per millimeter square, tubule diameter and tubular area. Laser treatment of exposed dentinal tubules with Er,Cr:YSGG promises a noninvasive, pain free and relatively safe treatment option.
\end{abstract}

Keywords: Er,Cr:YSGG laser, Dentinal hypersensitivity, Scanning electron microscope, Dentinal tubule occlusion, Diode lasers, Pain-free dentistry.

How to cite this article: Nandakumar A, lyer $\mathrm{VH}$. In vitro Analysis Comparing Efficacy of Lasers and Desensitizing Agents on Dentin Tubule Occlusion: A Scanning Electron Microscope Study. Int J Laser Dent 2014;4(1):1-7.

Source of support: Nil

Conflict of interest: None declared

\section{INTRODUCTION}

Dentinal hypersensitivity (DH) is one of the commonest causes of pain encountered in regular dental practice. The

\footnotetext{
${ }^{1,2}$ Private Practitioner

${ }^{1}$ Department of Laser Dentistry, Smile Dental Clinic, Chennai Tamil Nadu, India

${ }^{2}$ Fellowship and Diplomate in Laser Dentistry, Smile Dental Clinic, Chennai, Tamil Nadu, India

Corresponding Author: Arulmozhi Nandakumar, Private Practitioner, Department of Laser Dentistry, Smile Dental Clinic, Chennai, Tamil Nadu, India, Phone: 9003273438 e-mail: docarulmozhi@gmail.com
}

prevalence of $\mathrm{DH}$ in the population is found to be at a peak in the age of 20 to 40 years, ${ }^{1}$ more so in the buccocervical region of teeth due to branching of dentinal tubules at the dentinoenamel junction (DEJ). ${ }^{2}$ It has been described as the brief acute pain that cannot be attributed to any other dental disease. ${ }^{3,4}$ The stimulus evoking such a response is a cold stimulus and aggravated by mechanical trauma, such as brushing. ${ }^{5-7}$

Dentinal hypersensitivity, based on the causative factors, is best explained by Brännström's hydrodynamic theory. ${ }^{8}$ This theory attempts to explain the etiopathogenesis of $\mathrm{DH}$ and localization of the lesion in the dentin brought about by exposure of dentinal tubules as a result of enamel loss (abrasion, erosion and abfraction) and/or loss of periodontal coverage (gingival recession) which are the prerequisite for $\mathrm{DH} .{ }^{9}$ This is further supported by the substantiation that hypersensitive dentin has numerous number as well as wider dentinal tubules as compared to normal dentin. ${ }^{10,11}$ This causes increase fluid flow within the dentinal tubules and the pressure change stimulates $A \delta$ fibers, generating a sharp shooting pain. The loss of smear layer by brushing and chemicals makes the tubule system permeable toward the pulp-lesion initiation. ${ }^{12}$

Thus, the treatment modalities to curb sensitivity have two distinct approaches namely, to occlude the dentinal tubules making them less permeable and to modify neural transmission. The success of desensitizing agents is directly proportional to its ability to seal or occlude the dentinal tubules and reduce the diameter of the opened tubules thereby decreasing the hydrodynamic pain transmission mechanism. ${ }^{13}$ The scope of modification of causative factors in the management of dentinal hypersensitivity is one which is grossly overlooked. ${ }^{14}$ The oral environment being dynamic, the desensitizing agent has to withstand the challenges of salivary dissolution, acid attack from microbes and food components as well as chemical, mechanical and thermal trauma to provide long-lasting pain relief for the patient. ${ }^{15}$ All these warrant repeated application of dentifrices in order to reinforce their action which is lost by wear and tear. Thus, they fail to qualify under the criteria prescribed by Grossman as the requirement of a desensitizing agent. $^{16}$ 
Lasers, on the other hand, are a promising and upcoming treatment modality in management of DH. The action of lasers in DH depends on the laser wavelengths and parameters used. ${ }^{17}$ The effect of laser as desensitizing agent is exemplified only when etiological factors are removed. ${ }^{18}$ While low output lasers (He-Ne, diode, etc.) cause photobiomodulation in the dentin and bring about analgesia in the neural complex, ${ }^{19}$ high output lasers (Nd:YAG, Er:YAG, Er,Cr:YSGG) cause thermal changes which encourages recrystallization of dentin to cause occlusion of the tubules and formation of a smear layer which is much more resistant in the oral environment. ${ }^{20}$

\section{PROCEDURE}

A total of 60 teeth (canines and incisors) extracted from adult patients from 18 to 50 years was collected. The inclusion criteria were that the teeth were devoid of bacterial infection, did not have any restorations and carious lesions and the patients had not used desensitizing dentifrices in the last 3 months, or subjected to periodontal surgery in the last 6 months.

The samples were divided into three groups: A, B and C; each containing 20 teeth (Table 1). Each group was further subdivided into two subgroups of 10 teeth: the Er,Cr:YSGG subgroup (Fig. 1) and the diode subgroup (Fig. 2). The teeth in group A were treated only with lasers $(n=20)$, group B with lasers and Sensodyne repair and protect (Glaxosmithkline group of companies, India) $(n=20)$ and group $\mathrm{C}$ with laser and Sensodyne rapid relief (Glaxosmithkline group of companies, India) $(n=20)$.

After disinfection, the teeth were labeled in separate containers and preserved in normal saline. The dentin disk model was used for the study, ${ }^{21}$ the cervical region of the teeth was prepared using $2 \mathrm{~mm}$ round bur (BR-41, Mani Dia Burs), a box preparation of $2 \times 2 \times 2 \mathrm{~mm}$ was done. The teeth were etched using 17\% EDTA (Desmear, Anabond, Stedman, India) to remove the smear layer within the prepared box. In groups $\mathrm{B}$ and $\mathrm{C}$, the teeth were brushed for 6 minutes with desensitizing pastes followed by laser irradiation.

The teeth were washed with distilled water and were subjected to scanning electron microscopy (SEM) (S-3400N, Hitachi) (Fig. 3) analysis the same day after dehydration. Prior to SEM analysis, the samples were sputter coated with gold particles (Figs 4 and 5). Each tooth was examined at the cervical region under three magnifications of $2000 \times, 5000 \times$ and $10,000 \times$, and five images were obtained under each magnification. The SEM images were quantitatively and qualitatively analyzed using Image J (Version 1.47, National Institute of Health, USA)
Table 1: Teeth were divided into three subgroups (A to C) further divided into subgroups ( 1 and 2 )

\begin{tabular}{llll}
\hline & Group A (20) & Group B (20) & Group C (20) \\
\hline Subgroup 1 & $\begin{array}{l}\text { Er,Cr:YSGG } \\
\text { laser }\end{array}$ & $\begin{array}{l}\text { Er,Cr:YSGG } \\
\text { laser and } \\
\text { Sensodyne } \\
\text { repair and } \\
\text { protect }\end{array}$ & $\begin{array}{l}\text { Er,Cr:YSGG } \\
\text { laser and } \\
\text { Sensodyne } \\
\text { rapid relief }\end{array}$ \\
Subgroup 2 & Diode laser & $\begin{array}{l}\text { Diode laser } \\
\text { and } \\
\text { Sensodyne } \\
\text { repair and } \\
\text { protect }\end{array}$ & $\begin{array}{l}\text { Diode laser } \\
\text { and } \\
\text { Sensodyne } \\
\text { rapid relief }\end{array}$ \\
\hline
\end{tabular}

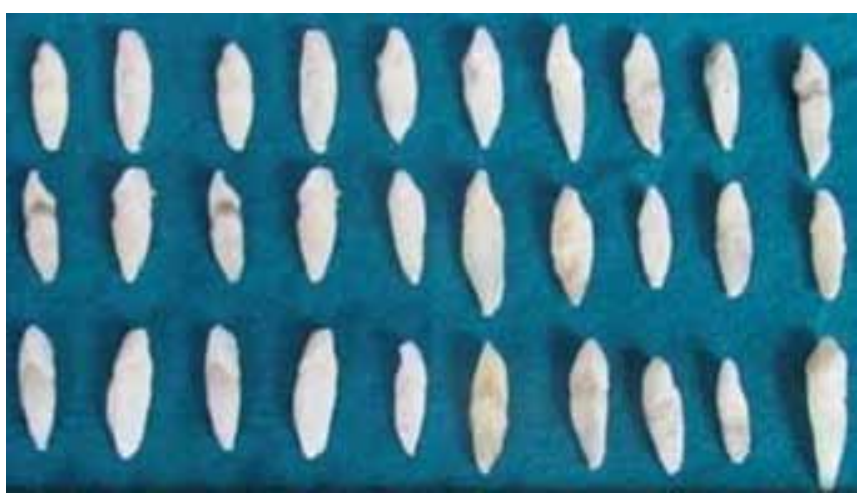

Fig. 1: Thirty teeth in the erbium subgroup

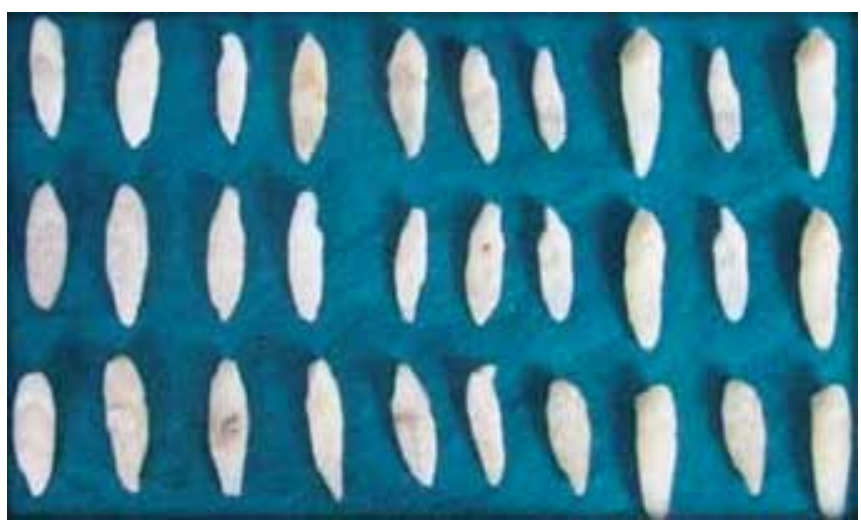

Fig. 2: Thirty teeth in the diode subgroup

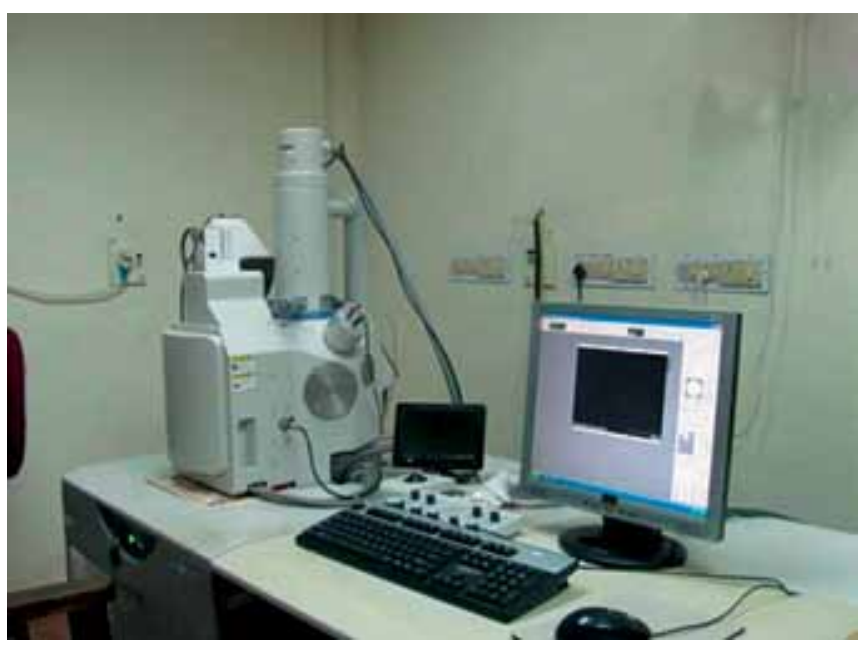

Fig. 3: Scanning electron microscope 


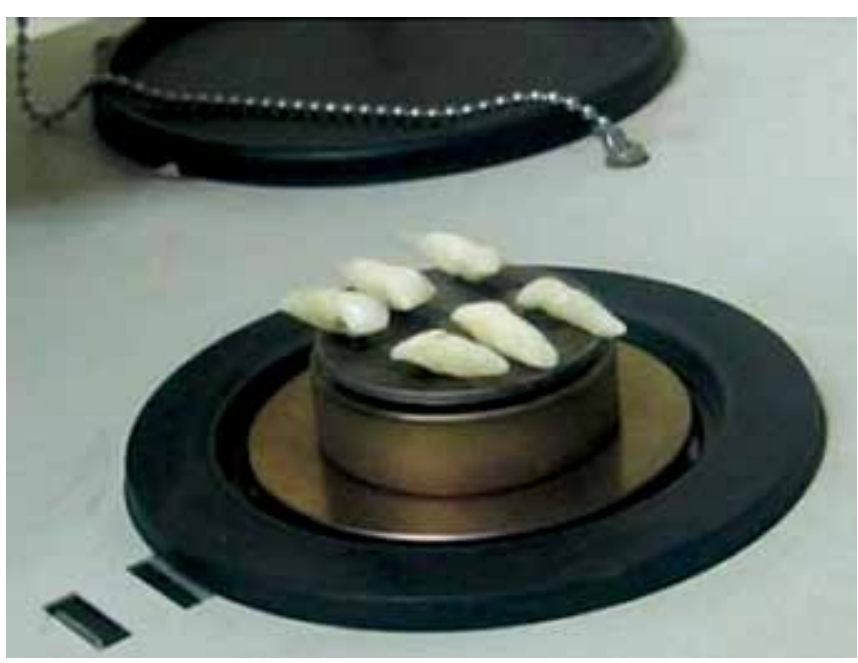

Fig. 4: Teeth mounted in SEM machine

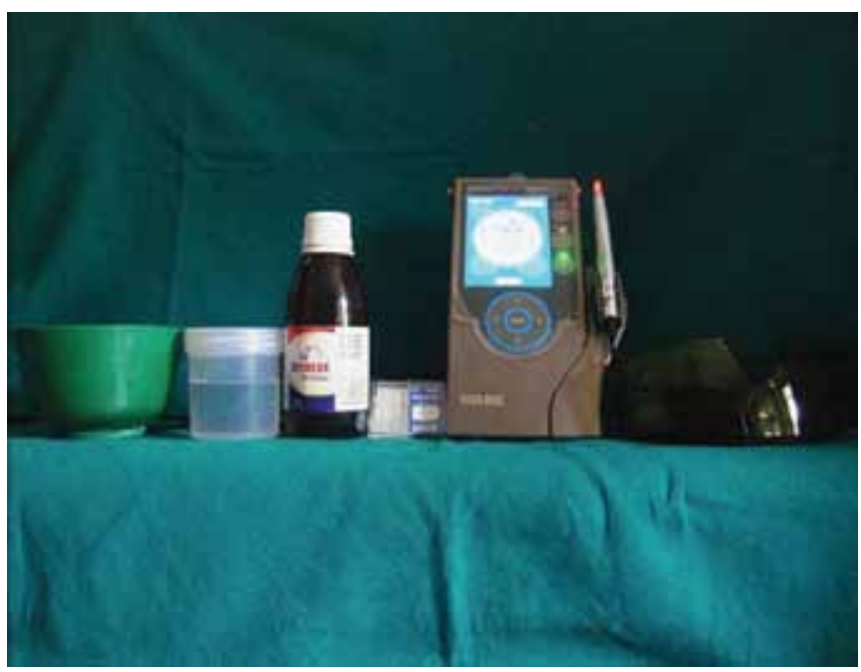

Fig. 6: $940 \mathrm{~nm}$ diode laser (Ezlase, Biolase, USA)

for number of tubules $/ \mathrm{mm}^{2}(\times 2,000$ magnification $)$ considering a total area of $40,000 \mu \mathrm{m}^{2}$, percentage of area occupied by opened tubules and the diameter of the tubules $(\times 5,000$ magnification).

\section{LASER EQUIPMENT}

The laser device used was $940 \mathrm{~nm}$ diode laser (Ezlase, Biolase, USA) (Fig. 6) at the laser parameters of $1 \mathrm{~W}$, continuous wave at $190 \mathrm{~J}$ for 15 seconds (Fig. 7) and $2780 \mathrm{~nm}$ Er,Cr:YSGG (Waterlase MD, Biolase, USA) (Fig. 8) at the laser parameters of $0.25 \mathrm{~W}, 50 \mathrm{~Hz}, 1 \%$ air and $1 \%$ water for 40 seconds (Fig. 9). Both the lasers were used in noncontact mode at about $1.5 \mathrm{~mm}$ away from the teeth. All laser safety precautions were used appropriately.

\section{RESULTS}

The microphotographic images from the SEM were qualitatively analyzed (Figs 10 to 15) and reveal completely or partially occluded tubules, with peritubular and intertubular dentin and surface cracks. The quality of smear

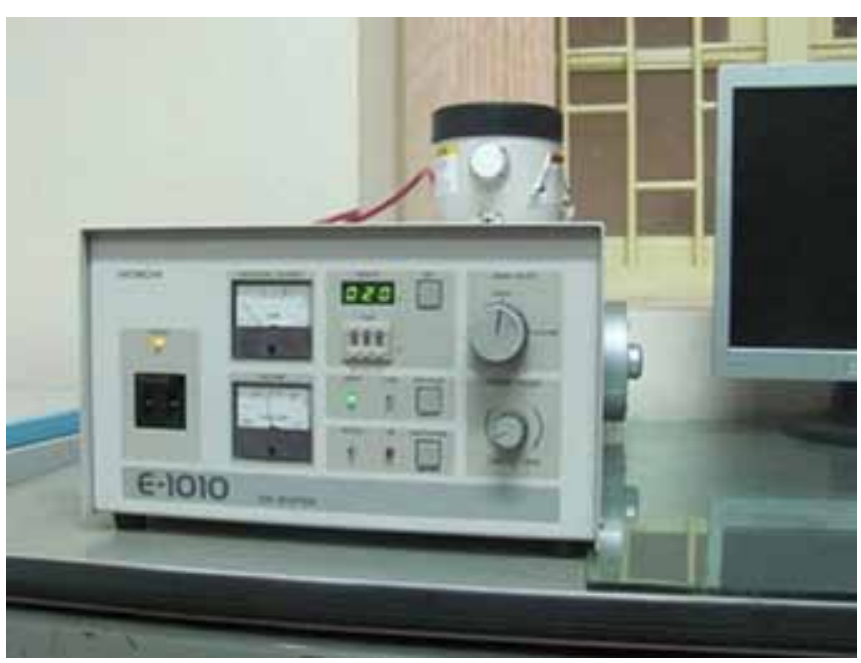

Fig. 5: Sputtering of the teeth with gold prior to SEM analysis

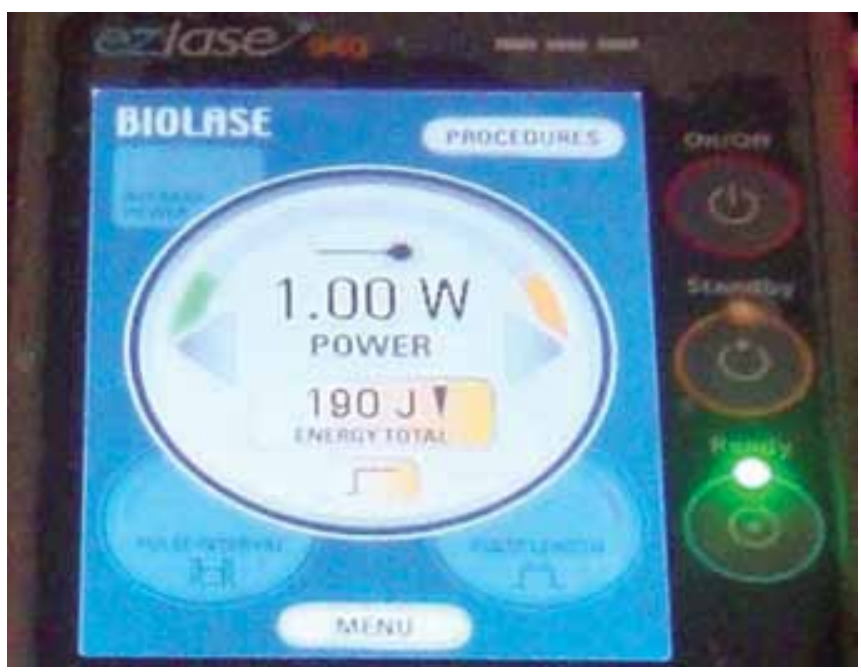

Fig. 7: Diode laser parameters used

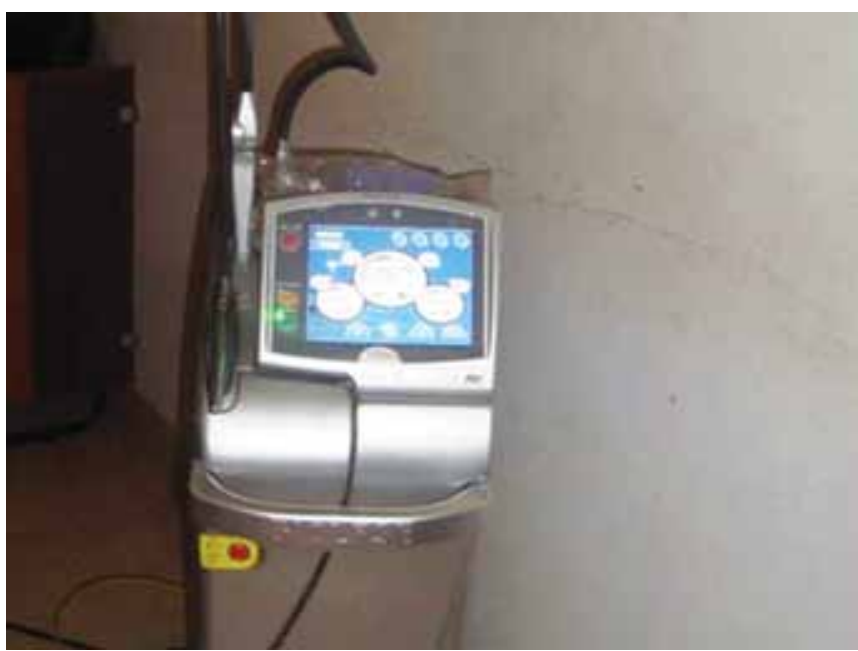

Fig. 8: $2780 \mathrm{~nm}$ Er,Cr:YSGG laser (Waterlase MD, Biolase, USA)

layer formed and number and quality of tubules occluded were best for the group irradiated with only Er,Cr:YSGG, and least favorable for specimens irradiated with diode and Sensodyne rapid relief. The laser group showed alteration 


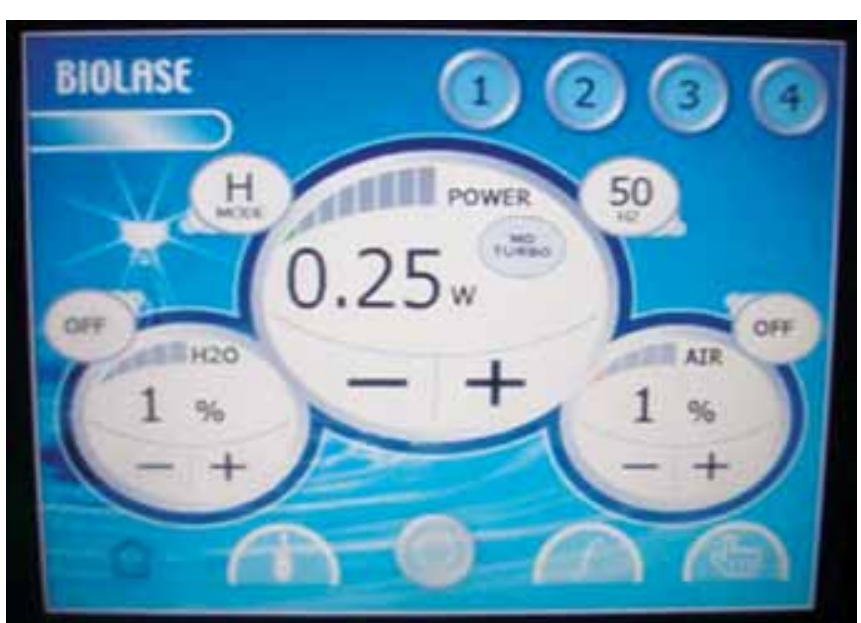

Fig. 9: Erbium laser parameters used

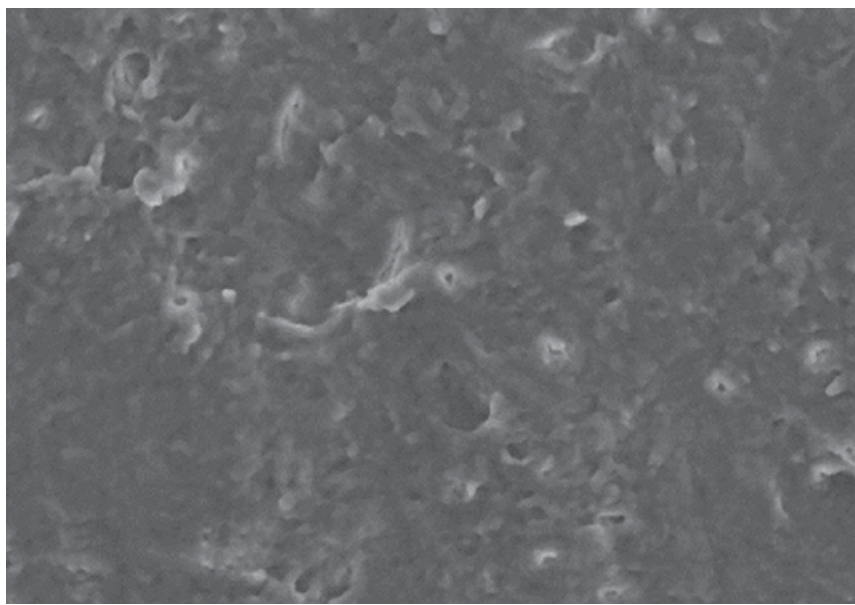

Fig. 11: Dentinal surface irradiated with diode laser at 2000x

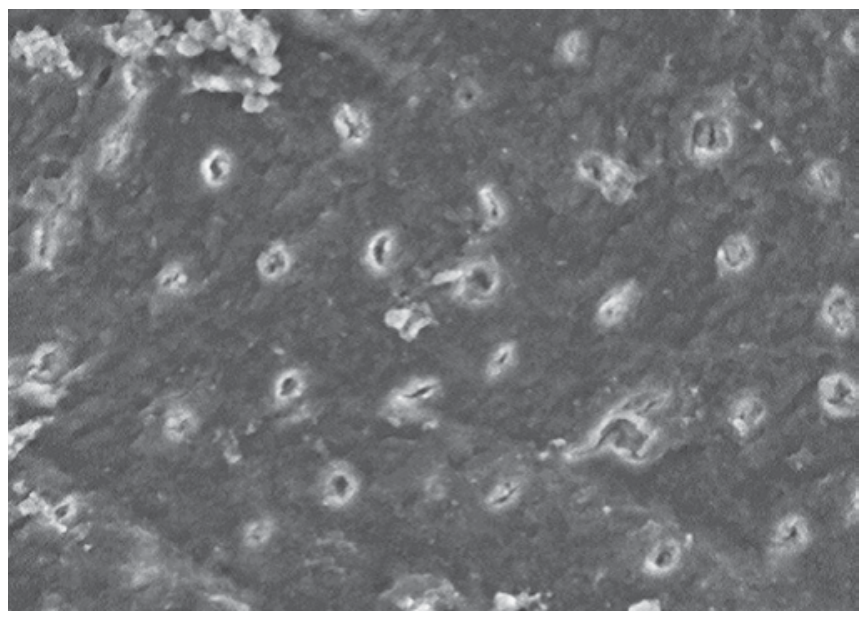

Fig. 13: Dentinal surface irradiated with diode laser after brushing with Sensodyne repair and protect at $2000 x$

of dentin surface and sealing of the opened tubules. The Sensodyne repair and protect group revealed a hybrid layer along with alteration in root dentinal surface in teeth treated in conjugation with Er,Cr:YSGG. The Sensodyne rapid relief though blocked the opened tubules to a comparatively lesser

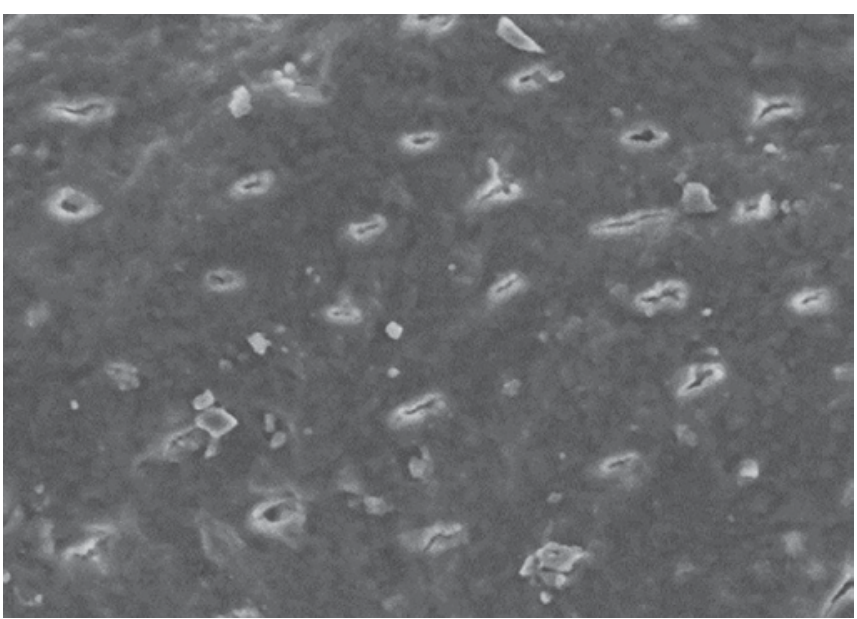

Fig. 10: Dentinal surface irradiated with Er,Cr:YSGG laser at 2000x

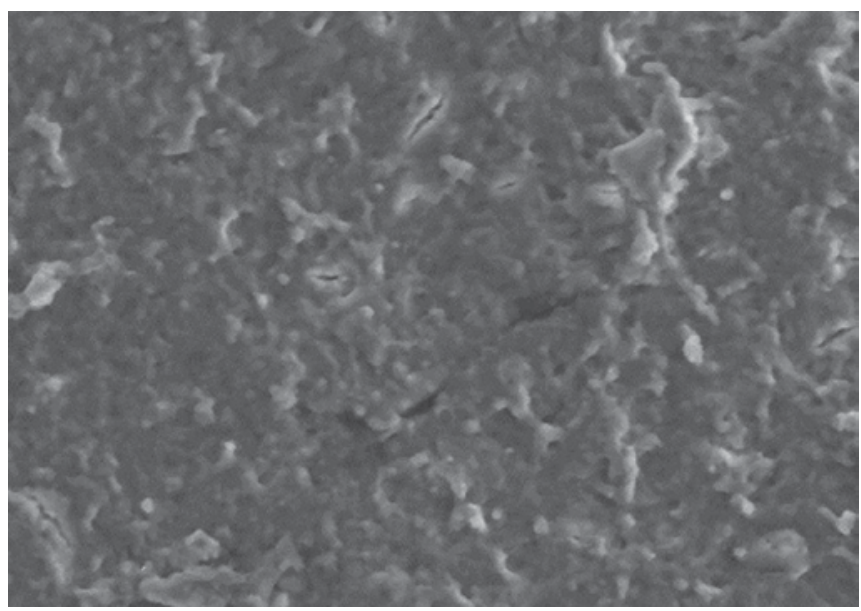

Fig. 12: Dentinal surface irradiated with Er,Cr:YSGG laser after brushing with Sensodyne repair and protect at 2000x

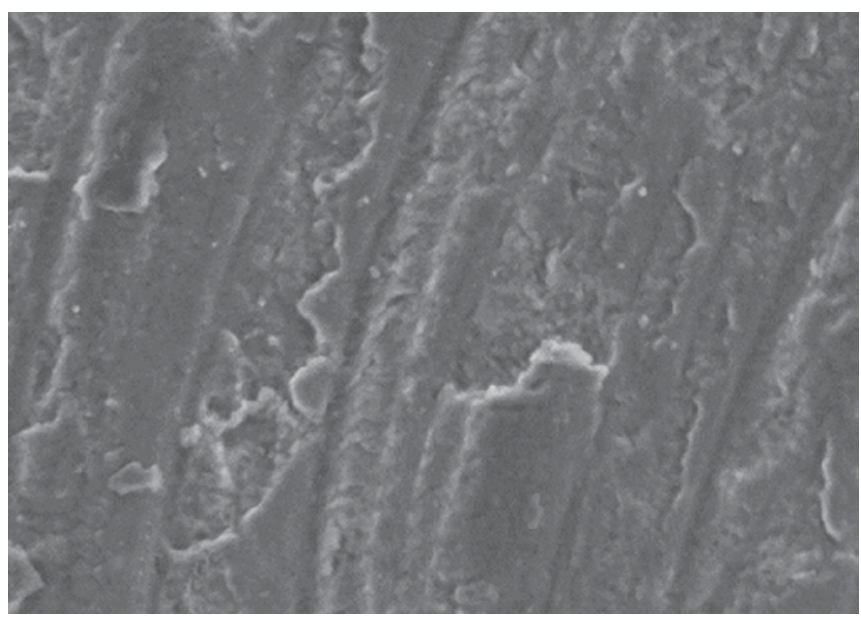

Fig. 14: Dentinal surface irradiated with Er,Cr:YSGG laser after brushing with Sensodyne rapid relief at 2000x

extent no integration with dentin was observed. The number of open tubules was also more in these teeth.

Quantitative analysis, using Image J (Version 1.47) image processing software, was accessed for three criteria namely number of tubules $/ \mathrm{mm}^{2}$, percentage of area occupied 


\begin{tabular}{llll}
\hline & Table 2: Quantitative analysis of the laser irradiated tooth & \\
\hline Group & $\begin{array}{l}\text { Avg. percentage of } \\
\text { open tubular area }\end{array}$ & $\begin{array}{l}\text { Avg. number of } \\
\text { tubules/mm }\end{array}$ & $\begin{array}{c}\text { Avg. diameter of } \\
\text { the tubules (nm) }\end{array}$ \\
\hline Er,Cr:YSGG & 8.62 & 5175 & 534 \\
Diode & 15.33 & 12675 & 741 \\
Er,Cr:YSGG + repair and protect & 17.50 & 10850 & 660 \\
Diode + repair and protect & 18.43 & 11150 & 717 \\
Er,Cr:YSGG + rapid relief & 21.56 & 18400 & 1.09 \\
Diode + rapid relief & 34.03 & 27225 & 1.13 \\
\hline
\end{tabular}

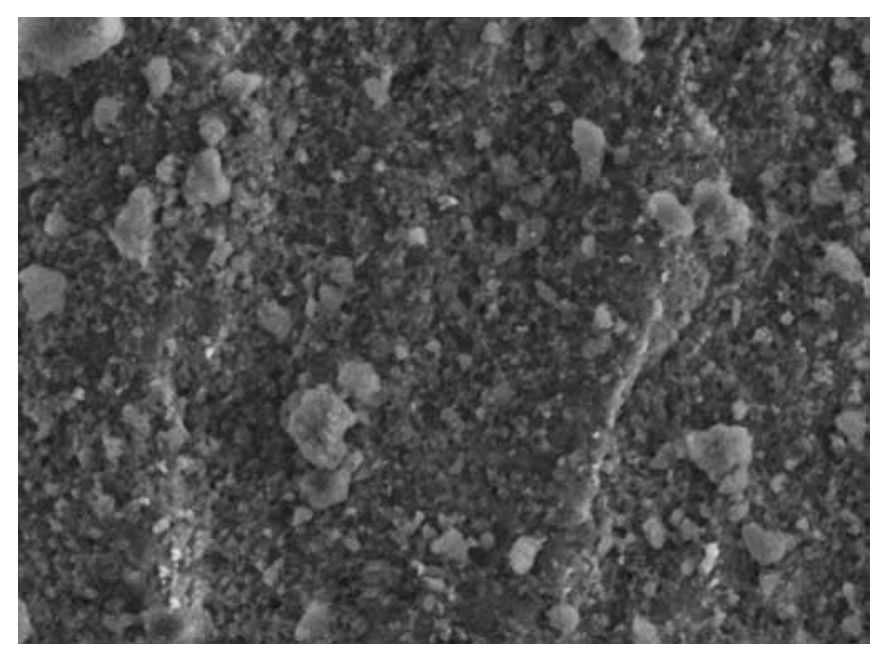

Fig. 15: Dentinal surface irradiated with diode laser after brushing with Sensodyne rapid relief at 2000x

by opened tubules and the diameter of the tubule (Table 2). The formula used to calculate the number of tubules was:

Number of tubules $/ \mathrm{mm}^{2}=$ counted number of tubules/ total area $\times 10^{6}$

In this study, the number of tubules $/ \mathrm{mm}^{2}$ for the Er,Cr:YSGG (group A subgroup 1) was the lowest5175 tubules as opposed to diode laser and Sensodyne rapid relief (group C subgroup 2) - 27,225 tubules. The Er,Cr:YSGG group also showed minimum percentage of tubular area of $8.6 \%$ and smallest diameter of the occluded tubule was $534 \mathrm{~nm}$.

\section{DISCUSSION}

The teeth most commonly affected by DH are canines, premolars, incisors and molars in the descending order, and, hence, these teeth were chosen for the study. ${ }^{22,23}$ The box preparation was done at the cervical region as the number of dentinal tubules is more numerous in that region. ${ }^{2}$

The dentin disk model, comprising of small dentin disks prepared from extracted teeth, has been used to study hydraulic conductance in dentin. The same has been adapted in this study to measure tubule occlusion after examination under SEM. ${ }^{24}$ The image was then digitalized and studied using image analysis software. This study was performed in vitro but, by including these dentin disks in intraoral appliances, the same can be studied simulating oral environment. ${ }^{25}$
Sensodyne rapid relief toothpaste containing strontium acetate proved to be superior to other desensitizing pastes in previous published studies ${ }^{26}$ hence, this was taken as a standard. The ability of strontium to deeply penetrate the hard tissues including dentin has contributed to its positive effects in hypersensitivity management. ${ }^{27}$ Nevertheless, strontium reduces the permeability within tubules by physically blocking them, but fails to bind to dentin. This warrants repeated applications to reinforce its action and easy dissolution in oral acids.

Bioactive and biocompatible glasses have a capacity to bond with bone tissue and enhance its growth and repair. ${ }^{28}$ These agents bond with the dentin after activation by the exposure to aqueous solutions. Exchange of sodium ions from the glass with hydrogen ions decreases the $\mathrm{pH}$ and aids in formation of a calcium-phosphate rich surface layer on the dentin. ${ }^{29}$ These desensitizing agents in conjugation with lasers were claimed to penetrate the tubules for up to $10 \mathrm{~mm}$ in previous studies. ${ }^{30}$ Sensodyne repair and protect, incorporating Novamin bioactive glass technology, was thus chosen for the study. ${ }^{31}$

Earlier studies have prescribed the repeated usage of desensitizing agents to ensure higher clinical effectiveness in dentinal tubule occlusion. ${ }^{13}$ In this study, activating the dentifrices with Er,Cr:YSGG after brushing for 6 minutes and analyzing through SEM reveals diminished tubule diameter of $660 \mathrm{~nm}$ as opposed to 5-day application when using dentifrice alone.

The chromophore for Er,Cr:YSGG is water, hence, this laser is equally applicable for soft and hard tissue procedures. Studies using Er,Cr:YSGG laser for treatment of DH are limited. The output power recommended for usage in $\mathrm{DH}$ is 0.25 to $0.5 \mathrm{~W} .{ }^{32}$ Keeping in mind to use the lowest possible power settings to ensure minimum collateral damage $0.2 \mathrm{~W}$ was chosen. Results in this study were consistent with those conducted previously. Yilmaz et al also demonstrated that the single application of Er,Cr:YSGG is effective in the management of $\mathrm{DH}^{33}$

The normal diameter of the dentinal tubule at the DEJ is 0.9 to $1 \mu \mathrm{m} .{ }^{34}$ The diameter of the tubules in teeth irradiated with Er,Cr:YSGG showed diameter value of $534 \mathrm{~nm}$. This could be explained by the surface alteration of peritubular 
dentin which causes occlusion of the dentinal tubules and result in reduction of their diameter. The tubules diameter in teeth irradiated with diode laser and sensodyne repair and protect show lesser diameter $(717 \mathrm{~nm})$ when compared to only diode irradiated teeth $(741 \mathrm{~nm})$. The calcium-phosphate like layer that binds to the dentin causes occlusion of the tubules and irradiation with diode cause additional thermal changes resulting in lesser diameter values when compared to only diode teeth.

The number of tubules/mm at the dentinoenamel junction is $20,000 / \mathrm{mm}^{2} .^{34}$ In this study, Er,Cr:YSGG irradiated teeth had only 5,175 tubules $/ \mathrm{mm}^{2}$. This clearly demonstrates that laser causes complete occlusion of tubules thus decreasing the number of tubules $/ \mathrm{mm}^{2}$. Supporting these values, the percentage of area occupied by open tubules was least (8.6\%) for the only $\mathrm{Er}, \mathrm{Cr}$ :YSGG group.

Comparing within the Er,Cr:YSGG subgroup, laser irradiation alone was found to be superior compared to the combined usage of desensitizing pastes followed by laser irradiation. Previous studies have shown contradicting results. A study using GaAlAs laser-830 nm along with fluoridation concluded $20 \%$ increased efficacy than laser alone. $^{35}$ Earlier studies have compared diode, Nd:YAG lasers with topical application of fluorides and found them superior. ${ }^{36}$ Research done with Er,Cr:YSGG are limited and hence results in this study were very promising and highlighted the use of only erbium lasers to be far superior to the use in conjuncture with desensitizing agents.

Within the limits of the present study on comparing the efficiency of erbium lasers $v s$ diode on treatment of dentinal surface, Er,Cr:YSGG showed superior results in terms of number of tubules per millimeter square, tubule diameter and tubular area. Groups A, B and C showed partially occluded tubules with group $\mathrm{C}$ subgroup 2 (diode and rapid relief) having the most number of open tubules. Inappropriate use of lasers with high power settings, prolonged exposure times and contact modes could result in high risk of tissue damage, causing thermal damage to the dental tissues and adjacent bone. ${ }^{37}$ This brings out the importance of meticulous documentation and follow-up of appropriate choice of laser wavelength and parameters to prove the efficacy of laser treatment in $\mathrm{DH}$.

\section{CONCLUSION}

Laser treatment of exposed dentinal tubules with Er,Cr:YSGG promises a noninvasive, pain-free and relatively safe treatment option with promising repeatable results. More longterm follow-up and studies in vivo are required before we can safely exclude the use of desensitizing agents completely and replace them with erbium lasers.

\section{ACKNOWLEDGMENT}

We extend our sincere thanks to Mr Srinivasan, Department of Mechanical Engineering, Anna University, Chennai, for helping us with the SEM imaging and Glaxosmithkline group of companies, India, for providing us samples during the study.

\section{REFERENCES}

1. Addy M. Dentine hypersensitivity: definition, prevalence distribution and aetiology. In: Addy M, Embery G, Edgar WM, Orchardson R, editors. Tooth wear and sensitivity: Clinical advances in restorative dentistry. London: Martin Dunitz 2000; 239-248.

2. Orchardson R, Collins WJ. Clinical features of hypersensitive teeth. Br Dent J 1987;162(7):253-256.

3. Addy M. Dentin hypersensitivity: new perspectives on an old problem. Int Dent J 2002;52(Suppl 5):367-375.

4. Canadian Advisory Board on dentin hepersensitivity consensusbased recommendation for the diagnosis and management of dentin hypersensitivity. J Can Dent Assoc 2003;69(4): 221-226.

5. Gillam DG, Seo HS, Newman HN, Bulman JS. Comparison of dentine hypersensitivity in selected occidental and oriental populations. J Oral Rehabil 2001;28(1):20-25.

6. Clayton DR, McCarthy D, Gillam DG. A study of the prevalence and distribution of dentine sensitivity in a population of 17 to 58 -year-old serving personnel on an RAF base in the midlands. J Oral Rehabil 2002;29(1):14-23.

7. Chidchuangchai W, Vongsavan N, Matthews B. Sensory transduction mechanisms responsible for pain caused by cold stimulation of dentine in man. Arch Oral Biol 2007;52(2): 154-160.

8. Brännström M. A hydrodynamic mechanism in the transmission of pain-producing stimuli through dentine. In: Anderson DJ, editor. Sensory mechanisms in dentine: Proceedings of a symposium, London, 1962 September 24. Oxford, England: Pergamon. 1963. p. 73-79.

9. Addy M, Hunter ML. Can tooth brushing damage your health? Effects on oral and dental tissues. Int Dent J 2003;53(Suppl 3): 177-186.

10. Absi EG, Addy M, Adams D. Dentine hypersensitivity: a study of the patency of dentinal tubules in sensitive and nonsensitive cervical dentine. J Clin Periodontol 1987;14(5):280-284.

11. Yoshiyama M, Noiri Y, Ozaki K, Uchida A, Ishikawa Y, Ishida H. Transmission electron microscopic characterization of hypersensitive human radicular dentin. J Dent Res 1990;69(6): 1293-1297.

12. Dababneh R, Khouri A, Addy M. Dentine hypersensitivity: an enigma: a review of terminology, epidemiology, mechanisms, aetiology and management. Br Dent J 1999;187(11):606-611.

13. Pinto SCS, Pochapski MT, Wambier DS, Pilatti GL, Santos FA. In vitro and in vivo analyses of the effects of desensitizing agents on dentin permeability and dentinal tubule occlusion, J Oral Science 2010;52(1):23-32.

14. Rees JS, Jin LJ, Lam S, Kudanowska I, Vowles R. The prevalence of dentine hypersensitivity in a hospital clinic population in Hong Kong. J Dent 2003;31(7):453-461.

15. Panduric V, Knez evic A tarle Z, S utalo J. The efficiency of dentine adhesives in treating non-caries cervical lesions. J Oral Rehabil 2001;28(12):1168-1174 
16. Grossman L. The treatment of hypersensitive dentine. J Am Dent Assoc 1935;22:592-602.

17. Ladalardo TC, Pinheiro A, Campos RA, Brugnera Júnior A, Zanin F, Albernaz PL. Laser therapy in the treatment of dentine hypersensitivity. Braz Dent J 2004;15(2):144-150.

18. Ciaramicoli MT, Carvalho RCR, Eduardo CP. Treatment of cervical dentin hypersensitivity using neodymium:yttriumaluminumgarnet laser: clinical evaluation. Lasers Surg Med 2003;33(5):358-362.

19. Asnaashari M, Moeini M. Effectiveness of Lasers in the Treatment of Dentin Hypersensitivity. J Lasers Med Sci 2013; 4(1):1-7.

20. Aranha A, Eduardo C. Effects of Er:YAG and Er,Cr:YSGG lasers on dentine hypersensitivity. Short-term clinical evaluation. Lasers Med Sci 2012;27(4):813-818.

21. Orchardson R, Gillam DG. Managing dentin hypersensitivity. J Am Dent Assoc 2006;137(7):990-998.

22. Hargreaves KM, Seltzer S. Pharmacological control of dental pain. Quientessence Publishing Inc. 2002. p. 205-225.

23. Addy M. Etiology and Clinical implication of dentine hypersensitivity. Dent Clin North Am 1990;34(3):503-514.

24. Mordan NJ, Barber PM, Gillam DG. The dentine disk: a review of its applicability as a model for the in vitro testing of dentine hypersensitivity. J Oral Rehabil 1997;24(2):148-156.

25. Banfield N, Addy M. Dentine hypersensitivity: development and evaluation of a model in situ to study tubule patency. J Clin Periodontol 2004;31(5):325-335.

26. Jain R, Jadhav S, Gangwal L, Hegde V. An in vitro evaluation of dental sealing efficacy of different laser activated desensitizing agents: a SEM investigation. J Dent Lasers 2011;5(2): 24-28.

27. Hodge HC, Gawett E, Thomas E. The adsorption of strontium at 40 degrees by enamel, dentine, bone and hydroxyapetite as shown by radioactive isotope. J Biol Chem 1946;163(1): $1-6$.

28. Hench LL, Splinter RJ, Allen WC, Greenlee TK. Bonding mechanism at the interface of ceramic prosthetic materials. Journal of biomedical Materials Research 1971;5(6):117-141.

29. Litkowski LJ, Hack GD, Shaeffer HB, Greenspan DC. Occlusion of Dentin tubules by 45S5 Bioglass Bioceramics 1997;10(441):441.

30. Kuo TC, Lee BS, Kang SH, Lin FH, Lin CP. Cytotoxicity of DPbioglass paste used for the treatment of dentin hypersensitivity. J Endod 2007;33:451-454.

31. Earl JS, Topping N, Elle J, Langford RM, Greenspan DC. Physical and chemical characteristics of dentin surface following NovaMin technology. J Clin Dent 2011;22 (Spec issue):62-67.

32. Gholami GA. Er;Cr:YSGG, Nd:YAG, $\mathrm{CO}_{2}$ and diode lasers on dentinal tubules: a scanning electron microscope in vitro study. Photomed Laser Surg 2011 Feb;29(2):115-121.

33. Yilmaz HG, Cengiz E, Kurtulmus-Yilmaz S, Leblebicioglu B. Effectiveness of Er,Cr:YSGG laser on dentine hypersensiti-vity: a controlled clinical trial. J Clin Periodontol 2011;38(4):341-346.

34. Garberoglio R, Brannstrom M. A scanning electron microscopic investigation of human dentinal tubules. Archives of Oral Biology 1976;21(6):355-362.

35. LiuHC, Lan WH. The combined effectiveness of the semiconductor lasers with Duraphat in the treatment of dentin hypersensitivity. Journal of Clinical Laser Medicine and Surgery 1994; 12(6):315-319.

36. Lan WH, Liu HC, Lin CP. The combined occluding effect of sodium fluoride varnish and $\mathrm{Nd}$ : YAG laser irradiation on human dentinal tubules. Journal of Endodontics 1999;25(6):424-426.

37. Schwarz F, Aoki A, Becker J, Sculean A. Laser application in non-surgical periodontal therapy: a systematic review. J Clin Periodontol 2008;35(58):29-44. 